\title{
Prognostic role of $A B O$ blood group in patients with unresectable hepatocellular carcinoma after transarterial chemoembolization
}

This article was published in the following Dove Press journal:

Therapeutics and Clinical Risk Management

\author{
Qing $\mathrm{Li}^{1, *}$ \\ Tao Wu ${ }^{1, *}$ \\ Xiao-An $\mathrm{Ma}^{2, *}$ \\ Li Jing' \\ Li-Li Han ${ }^{3}$ \\ Hui Guo' \\ 'Department of Medical Oncology, \\ The First Affiliated Hospital of \\ Xi'an Jiaotong University, Xi'an, \\ Shaanxi, People's Republic of China; \\ ${ }^{2}$ Department of General Surgery, \\ Xi'an Central Hospital, Xi'an, \\ Shaanxi, People's Republic of China; \\ ${ }^{3}$ Department of Oncology, The Second \\ Affiliated Hospital of Xi'an Jiaotong \\ University, Xi'an, Shaanxi, \\ People's Republic of China \\ *These authors contributed equally \\ to this work
}

\begin{abstract}
Background: The association of $\mathrm{ABO}$ blood group with prognosis of several malignancies has been established. However, its role in hepatocellular carcinoma (HCC) remains unclear.

Patients and methods: In this study, we investigated the prognostic role of ABO blood group in unresectable HCC patients receiving transarterial chemoembolization (TACE) as an initial treatment. Medical records of 2,611 HCC patients were collected, and clinical data of 282 unresectable HCC patients receiving TACE were ultimately analyzed retrospectively. A prognostic nomogram was generated for predicting 1-, 2-, and 3-year overall survival (OS) probability. A total of 114 (40.4\%), 69 (24.5\%), 64 (22.7\%), and 35 (12.4\%) HCC patients had blood groups $\mathrm{O}, \mathrm{A}, \mathrm{B}$, and $\mathrm{AB}$, respectively.

Results: The median OS times for patients with blood groups O, A, B, and AB were 24, 23, 20, and 20 months, respectively. Patients with blood group $\mathrm{AB}$ (hazard ratio $[\mathrm{HR}]=2.050,95 \%$ confidence interval $[\mathrm{CI}], 1.331-3.157, P=0.001)$ or group non-O (HR=1.479, 95\% CI, 1.110-1.972, $P=0.008$ ) had a poorer OS than those with blood group $\mathrm{O}$. The prognostic nomogram, with a $c$-index of 0.701 , was modest in predicting OS of unresectable HCC patients.

Conclusion: Patients with non-O blood group, particularly blood group $\mathrm{AB}$, had a worse OS compared with those having blood type $\mathrm{O}$. $\mathrm{ABO}$ blood group can predict the prognosis in patients with unresectable HCC undergoing TACE as an initial therapy. Further external validation in larger cohorts is necessary to confirm their usefulness in clinical practice.
\end{abstract}

Keywords: prognosis, ABO blood group, overall survival, liver cancer, transarterial chemoembolization

\section{Introduction}

Hepatocellular carcinoma (HCC) has been identified as one of the most common and lethal malignancies worldwide. ${ }^{1}$ Despite advances in diagnosis and treatment of $\mathrm{HCC}$, many patients with HCC still present with intermediate or advanced disease at diagnosis and thus cannot undergo surgical resection. For these patients, transarterial chemoembolization (TACE) is the mainstay of treatment strategy. ${ }^{2-4}$ However, median survival for these individuals is only $\sim 1$ year, much lower than expected. ${ }^{5}$ In addition, the prognoses of patients with unresectable stage HCC are variable due to the high heterogeneity in these populations. ${ }^{6}$ Therefore, efforts to identify new additional predictive markers are of great importance to improve the surveillance of prognosis for unresectable HCC.

Recently, there is increasing evidence showing that the ABO blood group is involved in the pathophysiology of various diseases such as cardiovascular and neoplastic disorders. ${ }^{7,8}$ The correlations of $\mathrm{ABO}$ blood group with survival have been evaluated 
in various types of malignancies, including nasopharyngeal carcinoma, ${ }^{9}$ ovarian cancer, ${ }^{10,11}$ colon cancer, ${ }^{12}$ and breast cancer. ${ }^{13}$ A risk of developing cancer of the pancreas, stomach, and pharynx has been shown using 1.6 million blood donors from Swedish and Danish populations. ${ }^{14}$ Also, another study showed that blood group non-O increased the risk of HCC. ${ }^{15}$ However, to date, very little is known concerning the association between $\mathrm{ABO}$ blood group and the survival for unresectable HCC patients.

To bridge the abovementioned gap, we performed a retrospective study to investigate the prognostic impact of $\mathrm{ABO}$ blood group in unresectable HCC patients who underwent TACE as their initial treatment in the Chinese population. The results of this study showed that patients with blood group non-O, particularly blood group $\mathrm{AB}$, had a worse overall survival (OS) than those with blood type O, suggesting that ABO blood group might be used for prognostic stratification and individualized surveillance.

\section{Patients and methods Patients}

This investigation was approved by the institutional review board (IRB) of the First Affiliated Hospital of Xi'an Jiaotong University. Written informed consent was obtained from all enrolled patients before the treatment. The methods were performed in accordance with the approved guidelines. After obtaining IRB approval, we retrospectively reviewed medical records of 2,611 patients with HCC between January 2008 and August 2013 at our institution. The inclusion criteria were as follows: patients whose initial treatment is TACE; patients without extra-hepatic spread; patients in whom liver function is Child-Pugh A and B; and patients without any other malignant tumors. Patients with unresectable HCC met at least one of the following criteria: patient's refusal resection, multiple lesions of the liver, and the presence of invasion of major blood vessels. Among 2,611 HCC patients in the database, a total of 282 unresectable $\mathrm{HCC}$ patients receiving TACE as an initial therapy were ultimately included.

\section{TACE procedures}

TACE procedures were performed by two experienced interventional radiologists following the standard practice. ${ }^{16}$ Briefly, hepatic arteriography was conducted to evaluate the tumor vessels. Subsequently, a catheter was selectively inserted into tumor-feeding artery to close the tumor. A mixture of lipiodol and chemotherapeutic agents (epirubicin and cisplatin) was administered into the tumor-feeding branch. The doses of anticancer agents were adjusted according to liver function and vasculature of the tumor. TACE procedures were repeated thereafter until the tumor was stable.

\section{Clinical variables}

Factors that may potentially be related to survival were collected, including age, sex, place of residence, liver cirrhosis, tumor size, differentiation, stage, Child-Pugh grades, hepatitis status, ascites, and pre-operative serum $\alpha$-fetoprotein (AFP) levels. Information on alcohol consumption and tobacco use was obtained from the patients. Their blood types were obtained from the medical records in the hospital.

\section{Study end points and survival data}

Serum AFP level, liver function, and computed tomography (CT) were performed every 3-4 months to assess treatment response. OS was defined as the time from the start of TACE to death from any cause or the last follow-up date. Patients who were still alive at the end of our follow-up were defined as censored data. Outcome data were collected until October 2014 or patient's death.

\section{Statistical analysis}

Data were analyzed using SPSS 23.0 for Windows (IBM Corporation, Armonk, NY, USA). Prognostic nomogram was constructed and analyzed by R 3.3 .1 with rms packages. ${ }^{39}$ Categorical data were grouped and analyzed by using the Pearson $\chi^{2}$ test. The Kaplan-Meier method was applied to estimate the cumulative OS rate, and the differences in survival distributions were tested by the log-rank test. Variables that affected OS $(P$-value $<0.05)$ on univariate analysis were subsequently included in multivariate analysis by using Cox's proportional hazards model. All tests were two-sided, and statistical significance was set at $P<0.05$.

\section{Results}

\section{Clinical characteristics}

The basic characteristics of enrolled patients are listed in Table 1 . This study included $282 \mathrm{HCC}$ patients (230 males and 52 females) following TACE as an initial treatment with a median age of 56 years (range: $22-82$ years). The distribution of ABO blood group was as follows: $\mathrm{O}$ in $114(40.4 \%)$ patients, $\mathrm{A}$ in $69(24.5 \%)$, B in $64(22.7 \%)$, and $\mathrm{AB}$ in 35 (12.4\%). Patient baseline characteristics were well balanced across individual ABO blood group, but significant differences were found between patients with blood type $\mathrm{O}$ and non-O group in terms of tumor staging (Table 1). 
Table I Clinicopathological characteristics of patients, stratified by ABO blood type

\begin{tabular}{|c|c|c|c|c|c|c|c|c|c|}
\hline \multirow[t]{2}{*}{ Variables, n (\%) } & \multirow{2}{*}{$\begin{array}{l}\text { Over } \\
\text { cohort }\end{array}$} & \multicolumn{4}{|c|}{ Blood group } & \multirow[t]{2}{*}{$P$-value } & \multicolumn{2}{|c|}{ Blood group } & \multirow[t]{2}{*}{$P$-value } \\
\hline & & 0 & A & B & AB & & 0 & Non-O & \\
\hline Total case & 282 & II 4 (40.4) & $69(24.5)$ & $64(22.7)$ & $35(12.4)$ & & I I 4 (40.4) & $168(59.6)$ & \\
\hline Median age (years) & & & & & & 0.782 & & & 0.922 \\
\hline$\geq 56$ & $142(50.4)$ & $57(50.0)$ & $36(52.2)$ & $34(53.1)$ & 15 (42.9) & & $57(50.0)$ & $85(50.4)$ & \\
\hline$<56$ & $140(49.6)$ & $57(50.0)$ & $33(47.8)$ & $30(46.9)$ & $20(57.1)$ & & $57(50.0)$ & $83(49.6)$ & \\
\hline Sex & & & & & & 0.665 & & & 0.749 \\
\hline Male & $230(81.6)$ & $94(82.5)$ & $57(82.6)$ & $49(76.6)$ & $30(85.7)$ & & $94(82.5)$ & $136(81.0)$ & \\
\hline Female & $52(18.4)$ & $20(17.5)$ & $12(17.4)$ & $15(23.4)$ & $5(14.3)$ & & $20(17.5)$ & $32(19.0)$ & \\
\hline Place of residence & & & & & & 0.492 & & & 0.142 \\
\hline Rural & $|3|(46.5)$ & $59(51.8)$ & $31(44.9)$ & $26(40.6)$ & $15(42.9)$ & & $59(51.8)$ & $72(42.9)$ & \\
\hline Urban & I5I (53.5) & $55(48.2)$ & $38(55 . I)$ & $38(59.4)$ & $20(57.1)$ & & $55(48.2)$ & $96(57.1)$ & \\
\hline Child-Pugh stage & & & & & & 0.726 & & & 0.705 \\
\hline A & $216(76.6)$ & $86(75.4)$ & $54(78.3)$ & 47 (73.4) & $29(82.9)$ & & $86(75.4)$ & I $30(77.4)$ & \\
\hline B & $66(23.4)$ & $28(24.6)$ & $15(21.6)$ & $17(26.6)$ & $6(17.1)$ & & $28(24.6)$ & $38(22.6)$ & \\
\hline Smoking & & & & & & 0.945 & & & 0.988 \\
\hline Never & $126(44.7)$ & $51(44.7)$ & $31(44.9)$ & $27(42.2)$ & $17(48.6)$ & & $5 \mathrm{I}(44.7)$ & $75(44.6)$ & \\
\hline Ever (former+current) & $156(55.3)$ & $63(55.3)$ & $38(55.1)$ & $37(57.8)$ & $18(5 \mid .4)$ & & $63(55.3)$ & $93(55.4)$ & \\
\hline Etiology & & & & & & 0.477 & & & 0.663 \\
\hline $\mathrm{HBV} / \mathrm{HCV}$ & $231(81.9)$ & $92(80.7)$ & $56(81.2)$ & $5 \mathrm{I}(79.7)$ & $32(91.4)$ & & $92(80.7)$ & 139 (82.7) & \\
\hline None & $51(19.1)$ & $22(19.3)$ & $13(19.8)$ & $13(20.3)$ & $3(8.6)$ & & $22(19.3)$ & $29(17.3)$ & \\
\hline Serum AFP level (ng/mL) & & & & & & 0.422 & & & 0.245 \\
\hline$<400$ & | 44 (5।. 1$)$ & $63(55.3)$ & $31(44.9)$ & $30(46.9)$ & $20(57.1)$ & & $63(55.3)$ & 81 (48.2) & \\
\hline$>400$ & I 38 (48.9) & 51 (44.7) & $38(55.1)$ & $34(53.1)$ & $15(42.9)$ & & 51 (44.7) & $87(51.8)$ & \\
\hline PVTT & & & & & & 0.280 & & & 0.079 \\
\hline Yes & $85(30.1)$ & $41(36.0)$ & $16(23.3)$ & $17(26.6)$ & II (3I.4) & & $4 I(36.0)$ & $44(26.2)$ & \\
\hline No & $197(69.9)$ & $73(64.0)$ & $53(76.8)$ & $47(73.4)$ & $24(68.8)$ & & $73(64.0)$ & $124(73.8)$ & \\
\hline Liver cirrhosis & & & & & & 0.343 & & & 0.852 \\
\hline Yes & $207(73.4)$ & $83(72.8)$ & $48(69.6)$ & $46(71.9)$ & $30(85.7)$ & & $83(72.8)$ & $124(73.8)$ & \\
\hline No & $75(26.6)$ & $31(27.2)$ & $21(30.4)$ & $18(28.1)$ & $5(14.3)$ & & $31(27.2)$ & $44(26.2)$ & \\
\hline Ascites & & & & & & 0.126 & & & 0.273 \\
\hline Yes & 87 (30.9) & $31(27.2)$ & $23(33.3)$ & $26(40.6)$ & $7(20.0)$ & & $31(27.2)$ & $56(33.3)$ & \\
\hline No & $195(69.1)$ & $83(72.8)$ & $46(66.7)$ & $38(59.4)$ & $28(80.0)$ & & $83(72.8)$ & $112(66.7)$ & \\
\hline Tumor size $(\mathrm{cm})$ & & & & & & 0.419 & & & 0.417 \\
\hline$\leq 5$ & I I8 (4I.8) & $5 I(44.7)$ & $30(43.5)$ & $21(32.8)$ & $16(45.7)$ & & $5 I(44.7)$ & 67 (39.9) & \\
\hline$>5$ & $164(58.2)$ & $63(55.3)$ & $39(56.5)$ & $43(67.2)$ & $19(54.3)$ & & $63(55.3)$ & $101(60.1)$ & \\
\hline Tumor stage & & & & & & 0.678 & & & 0.012 \\
\hline $\mathrm{I}+\mathrm{II}$ & $69(24.5)$ & $19(16.7)$ & $23(33.3)$ & $17(26.6)$ & $10(28.6)$ & & $19(16.7)$ & $50(29.8)$ & \\
\hline III+IV & $213(75.5)$ & $95(83.3)$ & $46(66.7)$ & $47(73.4)$ & $25(71.4)$ & & $95(83.3)$ & I I 8 (70.2) & \\
\hline
\end{tabular}

Note: Tumor stage, TNM seventh edition.

Abbreviations: AFP, $\alpha$-fetoprotein; HBV, hepatitis B virus; $\mathrm{HCV}$, hepatitis $\mathrm{C}$ virus; PVTT, portal vein tumor thrombus.

\section{Correlation of OS with $\mathrm{ABO}$ blood group status}

Among the 282 patients, there were 212 deaths after a median follow-up of 22 months (range: 4-67 months). The 1-, 2-, and 3-year OS rates for the cohort were $81.2 \%, 43.2 \%$, and $22.6 \%$, respectively. The median OS times were as follows: blood group O, 24 months (95\% confidence interval [CI], 20.05-27.95 months); blood group A, 23 months (95\% CI, 19.83-26.16 months); blood group B, 20 months (95\% CI, 17.23-22.76 months); blood group AB, 20 months (95\% CI, 14.52-25.47 months). As shown in Figure 1A, there were no statistically significant differences between individual ABO blood group and OS $(P=0.095)$. Notably, patients with blood group $\mathrm{O}$ had more favorable $\mathrm{OS}$ than patients with blood group $\mathrm{A}, \mathrm{B}$, or $\mathrm{AB}$. Therefore, we divided the entire cohort into two subgroups (blood group $\mathrm{O}$ vs non-O [A, B, and $\mathrm{AB}]$ ). The median OS was 24 months (95\% CI, 20.05-27.95 months) for patients with blood group $\mathrm{O}$ and 21 months $(95 \% \mathrm{CI}$, 18.46-23.53 months) for patients with blood group non-O. As shown in Figure 1B, the OS of patients with blood groups $\mathrm{O}$ and non-O was significantly different $(P=0.032)$.

\section{Univariate and multivariate analyses}

The univariate analyses suggested that Child-Pugh stage $(P<0.001)$, serum AFP concentration $(P=0.001)$, portal vein tumor thrombus $(P=0.050)$, stage $(P<0.001)$, ascites 
A

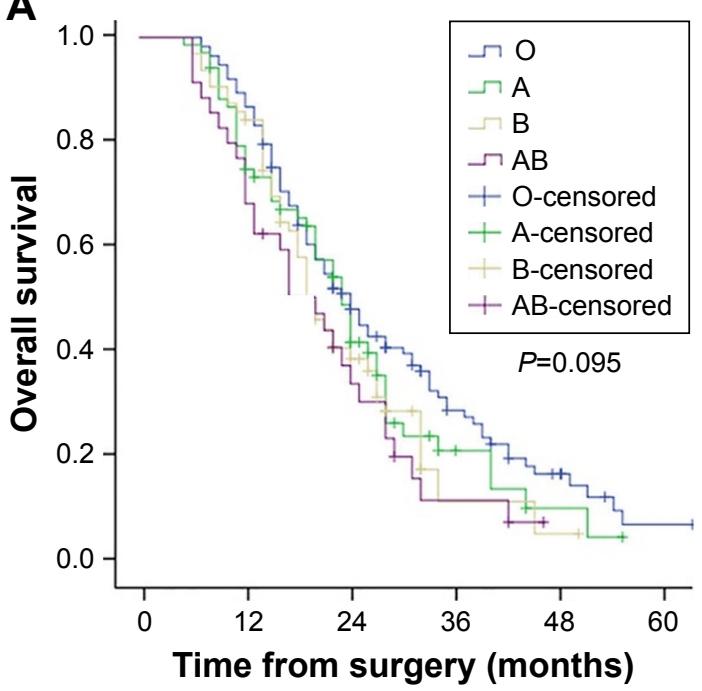

Number at risk

$\begin{array}{lllllll}\text { Blood type O } & 114 & 99 & 47 & 23 & 8 & 2 \\ \text { Blood type A } & 69 & 50 & 22 & 6 & 2 & 0 \\ \text { Blood type B } & 64 & 53 & 18 & 2 & 0 & 0 \\ \text { Blood type AB } & 35 & 24 & 10 & 2 & 0 & 0\end{array}$

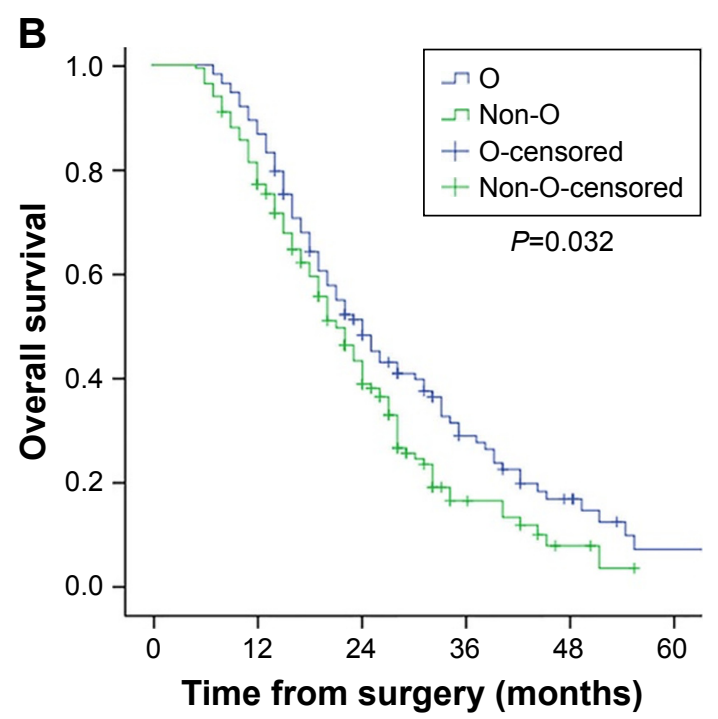

Number at risk

$\begin{array}{lllllll}\text { Blood type O } & 114 & 99 & 47 & 23 & 8 & 2\end{array}$

$\begin{array}{lllllll}\text { Blood type non-O } & 168 & 127 & 50 & 10 & 2 & 0\end{array}$

Figure I Kaplan-Meier survival analysis for OS: (A) different ABO blood groups and (B) blood groups $\mathrm{O}$ and non-O.

Abbreviation: OS, overall survival.

( $P=0.001)$, tumor size $(P=0.006)$, and blood group (group $\mathrm{AB}$ vs group $\mathrm{O}, P=0.028$; group non-O vs group $\mathrm{O}, P=0.037$ ) were prognostic predictors of OS. Further multivariate analyses identified serum AFP level, tumor stage, tumor size, and ascites as significant prognostic factors of OS. Specifically, compared to blood group $\mathrm{O}$, the hazard ratios (HRs) for patients with blood group $\mathrm{AB}$ or non-O were 2.050 (95\% CI, $1.331-3.157, P=0.001)$ and $1.479(95 \% \mathrm{CI}, 1.110-1.972$, $P=0.008$ ), respectively, suggesting that these HCC patients with blood group $\mathrm{AB}$ or non-O have a worse survival. The details of this analysis are depicted in Table 2.

\section{Prognostic nomogram for OS}

As shown in Figure 2, we further conducted a nomogram to predict the probability of death for individual HCC patients within 1, 2, and 3 years after TACE. The significant prognostic variables (AFP level, tumor stage, tumor size, ascites, and blood group) were used to build the nomogram. Calibration curves for nomogram are shown in Figure 3, which performed well with the ideal model. Harrell's $c$-index was 0.701 for OS, indicating that the nomogram had an excellent predictive accuracy.

\section{Discussion}

Prognostic biomarkers are expected to guide therapeutic options and surveillance strategies. Although prognostic factors have been identified for the whole HCC population, including AFP, tumor size, vascular invasion, and cirrhosis, useful clinical factors are not validated for predicting the outcomes of unresectable HCC receiving TACE.${ }^{17}$ Recently, $\mathrm{ABO}$ blood group has been reported to correlate with increasing the risk of HCC. ${ }^{18,19}$ However, few investigations have examined its prognostic role in unresectable HCC patients following TACE. Therefore, we assess the association of $\mathrm{ABO}$ blood group and the prognosis of unresectable $\mathrm{HCC}$ patients who underwent TACE as an initial treatment in the Chinese population for the first time.

In this study, the results suggested that patients with $A B$ blood group or non-O have a poorer OS than those with blood group O. Also, we developed a novel nomogram incorporating tumor stage, tumor size, ascites, serum AFP level, and blood type, which predicts OS for HCC patients receiving TACE more precisely. Our results are consistent with the previous findings in nasopharyngeal carcinoma, ${ }^{20}$ pancreatic, and renal cancer patients. ${ }^{21,22}$ These studies indicated that the clinical outcome of patients with blood $\mathrm{O}$ is better than that of non-O patients. Particularly, individuals with blood group non-O may have a genetic background that predisposes to the risk of cancer. A recent large-scale epidemiologic study reported that blood group A correlated with the elevated risk of stomach cancer and blood group non-O correlated with the development of pancreatic cancer. ${ }^{23}$ Similarly, Kakava et al ${ }^{24}$ showed that head and neck cancer was more common in a population with blood group 
Table 2 Cox regression analysis of potential prognosticators

\begin{tabular}{|c|c|c|c|c|}
\hline \multirow[t]{2}{*}{ Variables } & \multicolumn{2}{|l|}{ Univariate analysis } & \multicolumn{2}{|c|}{ Multivariate analysis } \\
\hline & HR (95\% Cl) & $P$-value & HR (95\% Cl) & $P$-value \\
\hline \multicolumn{5}{|l|}{ Age (years) } \\
\hline$\geq 56$ vs $<56$ & I.I 79 (0.899-I.545) & 0.233 & & \\
\hline \multicolumn{5}{|l|}{ Sex } \\
\hline Male vs female & $0.916(0.653-1.286)$ & 0.612 & & \\
\hline \multicolumn{5}{|l|}{ Place of residence } \\
\hline Rural vs urban & $1.302(0.99|-| .7 \mid I)$ & 0.058 & & \\
\hline \multicolumn{5}{|l|}{ Smoking } \\
\hline \multicolumn{5}{|l|}{ (former+current) } \\
\hline \multicolumn{5}{|l|}{ Child-Pugh stage } \\
\hline$A$ vs $B$ & $0.578(0.425-0.787)$ & $<0.001$ & $0.823(0.589-|| 5 \mid)$. & 0.254 \\
\hline \multicolumn{5}{|l|}{ Etiology } \\
\hline HBV/HCV vs none & $0.954(0.676-1.347)$ & 0.791 & & \\
\hline \multicolumn{5}{|c|}{ Serum AFP level $(\mathrm{ng} / \mathrm{mL})$} \\
\hline$\leq 400$ vs $>400$ & $0.624(0.474-0.822)$ & 0.001 & $0.657(0.496-0.87 I)$ & 0.003 \\
\hline \multicolumn{5}{|l|}{ PVTT } \\
\hline Yes vs no & 1.331 (I.000-1.77I) & 0.050 & I.I33 (0.828-I.549) & 0.436 \\
\hline \multicolumn{5}{|l|}{ Liver cirrhosis } \\
\hline Yes vs no & $1.250(0.916-1.707)$ & 0.159 & & \\
\hline \multicolumn{5}{|l|}{ Ascites } \\
\hline Yes vs no & $2.109(1.615-2.886)$ & $<0.001$ & 1.911 (I.40I-2.605) & $<0.001$ \\
\hline \multicolumn{5}{|l|}{ Tumor size $(\mathrm{cm})$} \\
\hline$>5$ vs $\leq 5$ & $1.482(1.122-1.957)$ & 0.006 & 1.457 (I.094-1.942) & 0.010 \\
\hline \multicolumn{5}{|l|}{ Tumor stage } \\
\hline I+II vs III+IV & $0.458(0.325-0.646)$ & $<0.001$ & $0.470(0.325-0.680)$ & $<0.001$ \\
\hline \multicolumn{5}{|l|}{ Blood group } \\
\hline A vs $O$ & $1.210(0.853-1.718)$ & 0.286 & I.364 (0.947-I.967) & 0.096 \\
\hline B vs O & $1.372(0.953-1.974)$ & 0.089 & $1.349(0.93 \mathrm{I}-1.953)$ & 0.114 \\
\hline$A B$ vs $O$ & $1.610(1.054-2.460)$ & 0.028 & $2.050(1.33 \mid-3.157)$ & 0.001 \\
\hline Non-O vs O & $1.345(1.018-1.777)$ & 0.037 & 1.479 (1.1 I0-1.972) & 0.008 \\
\hline
\end{tabular}

Abbreviations: $\mathrm{Cl}$, confidence interval; HBV, hepatitis B virus; HCV, hepatitis C virus; HR, hazard ratio; PVTT, portal vein tumor thrombus.

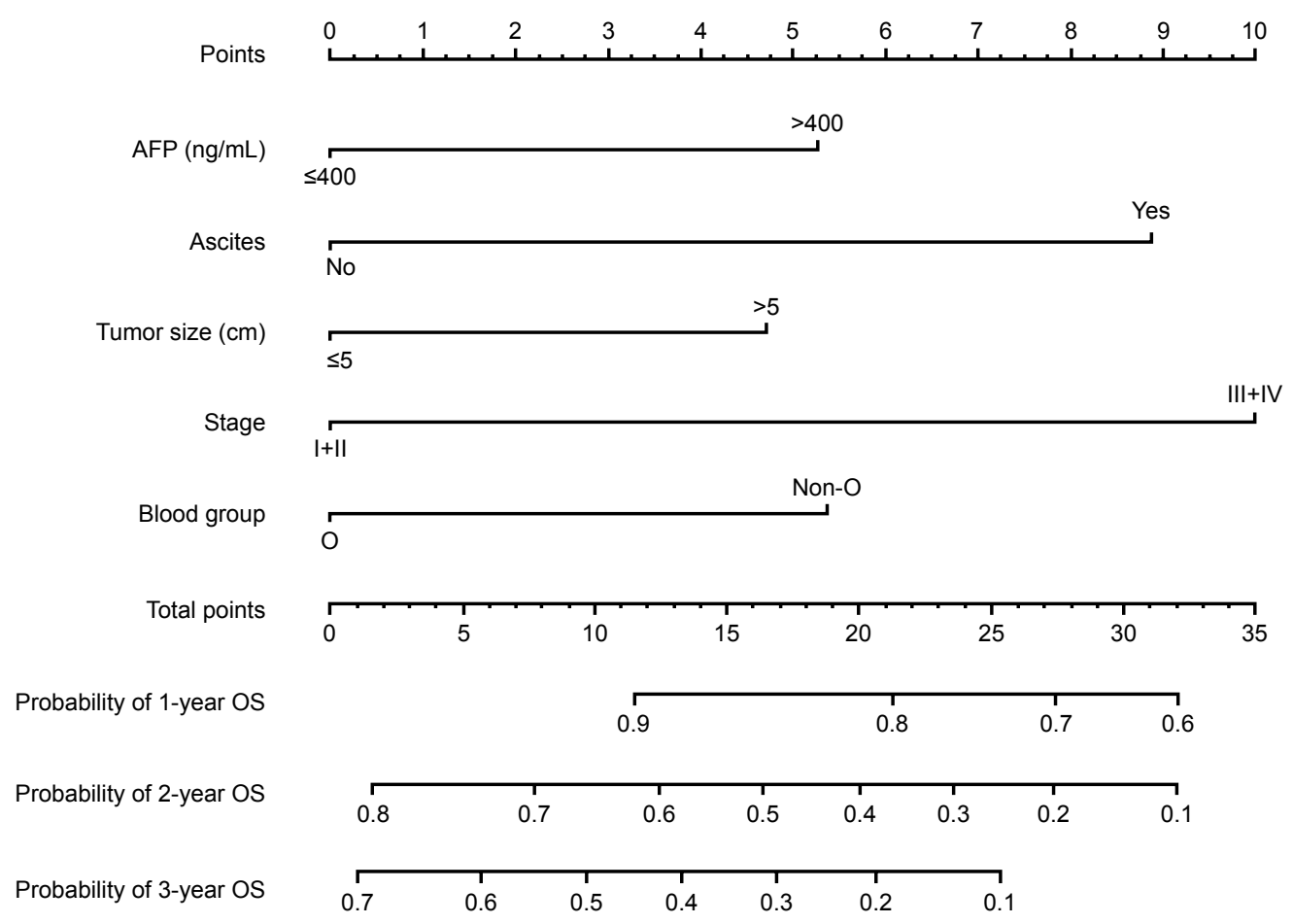

Figure 2 Nomogram predicting I-, 2-, and 3-year OS probability.

Abbreviations: AFP, $\alpha$-fetoprotein; OS, overall survival. 

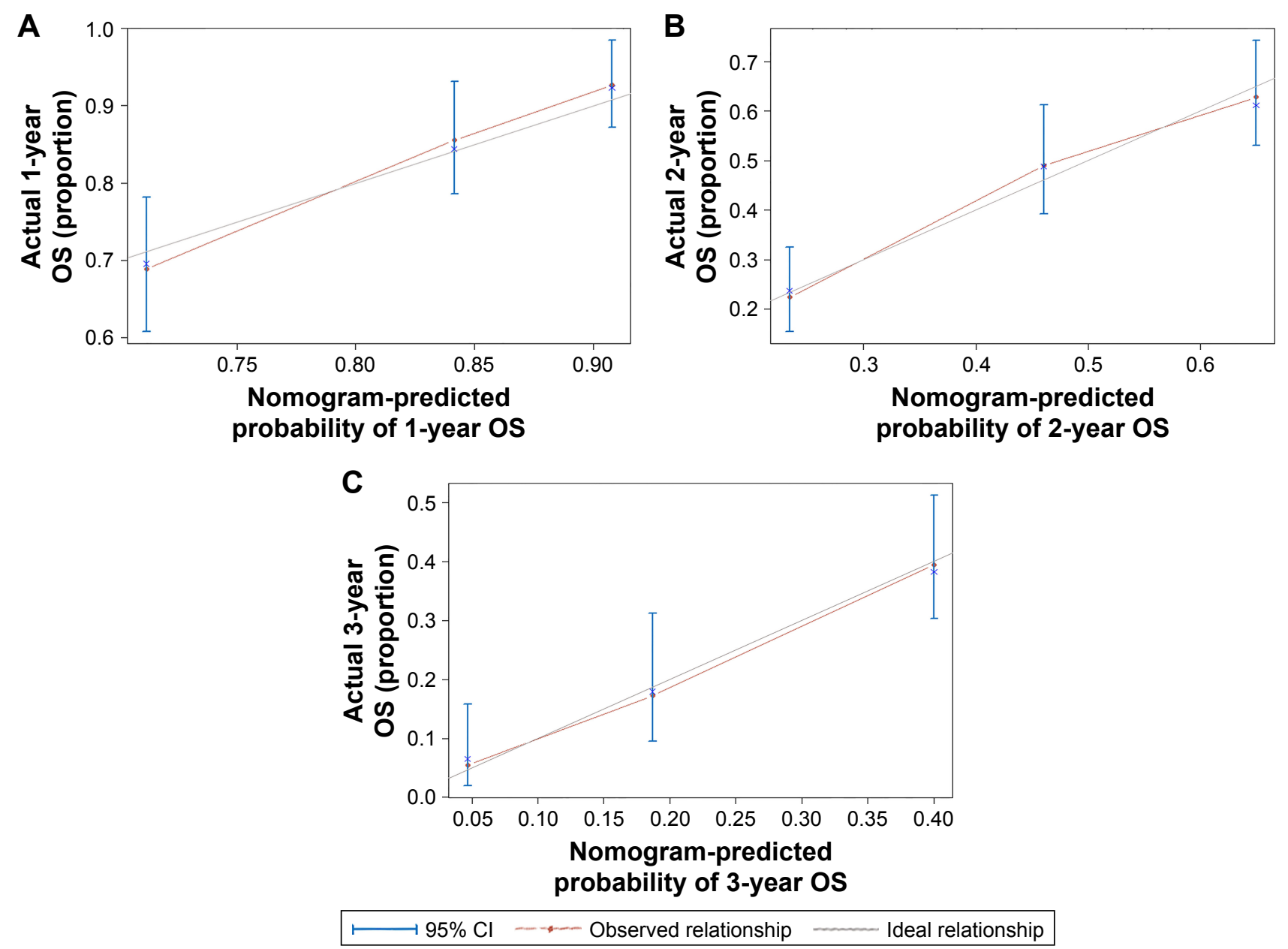

Figure 3 Calibration of nomogram-predicted OS probability: (A) the probability of I-year OS; (B) the probability of 2-year OS; (C) the probability of 3-year OS. Abbreviations: $\mathrm{Cl}$, confidence interval; $\mathrm{OS}$, overall survival.

A compared to other blood groups. Another study indicated that blood group A was related to the increased risk of developing glioblastoma, while blood group $\mathrm{O}$ reduced the risk. ${ }^{25}$ However, some research suggested that $\mathrm{ABO}$ blood group had no significant prognostic impact on non-small-cell lung cancer, ${ }^{26}$ urothelial carcinoma of the bladder, ${ }^{27}$ and triplenegative breast cancer. ${ }^{28}$ Racial variability, heterogeneity of blood group distribution, and differences in demographics may lead to these conflicting results.

The underlying mechanisms by which $\mathrm{ABO}$ blood group influences the survival of HCC patients remain largely unknown. Several hypotheses may explain the underlying biological basis. $\mathrm{ABO}$ antigens have been recognized for their role as cancer-associated antigens. ${ }^{29,30}$ Terada and Nakanuma ${ }^{31}$ revealed that $\mathrm{ABO}$ antigens are usually present on $\mathrm{HCC}$ tissue but not expressed on normal liver. Thus, the aberrant antigen changes might be involved in HCC progression. Second, non-O blood group individuals have higher circulating plasma levels of vWF and factor VIII, and consequently contribute to developing venous thromboembolism. ${ }^{32}$ These coagulation factors are modulators of angiogenesis and are involved in carcinogenesis. ${ }^{33}$ In addition, hypercoagulability plays significant roles in tumor metastasis and poor prognosis. ${ }^{34}$ Third, there is a close link between blood group antigens and systemic inflammation response, which facilitates the development and progression of HCC. Studies revealed that single-nucleotide polymorphisms (SNPs) at the ABO gene locus correlated with circulating levels of inflammatory markers, including tumor necrosis factor-alpha (TNF- $\alpha$ ) and soluble intercellular adhesion molecule-1 (sICAM-1). ${ }^{35}$ These inflammatory cytokines are involved in the regulation of hepatocarcinogenesis. Particularly, sICAM-1 has been associated with occurrence and prognosis of HCC. ${ }^{36}$ The low sICAM-1 level may promote tumor progression. ${ }^{37}$ Individuals with non-O blood group express low level of sICAM-1 in comparison with those with blood group O. ${ }^{38}$ These biological bases may partially explain the correlation of blood group with OS of HCC. 
To the best of our knowledge, there are few reports on the association of blood group and survival for HCC. Moreover, it remains unclear whether blood group plays a role in the biological behavior of HCC cells or the TACE surgery process. Further investigations are needed to figure out these questions. The present study can provide an important reference for future research and can inspire more works to explore the correlation and mechanism between blood group and prognosis of HCC.

There are several limitations in this study. First, the patient cohort in this retrospective study is not representative of the general population. Selection bias may exist. Second, although ABO blood group is linked to race, the ethnic makeup in this study is Chinese, perhaps limiting the universality of our findings. Third, because sample size of the study was relatively small, we did not explore the impact of $\mathrm{ABO}$ blood group on survival based on different clinicopathological features. Despite the abovementioned limitations, the results of this study expand the current understanding of the relationship between $\mathrm{ABO}$ blood group and prognosis of HCC. Obtaining serum blood type is convenient; the effect of blood group on tumor biology or response to therapy should be further explored.

\section{Conclusion}

ABO blood group correlates with the prognosis of patients receiving TACE as an initial treatment for unresectable HCC. Patients with blood group non-O, particularly blood group $\mathrm{AB}$, had a worse OS than those with blood group $\mathrm{O}$. Further clinical and experimental investigations are necessary to confirm this association and to elucidate the related mechanisms.

\section{Acknowledgment}

This study was supported by the National Natural Science Foundation of China Program (No 81372581).

\section{Disclosure}

The authors report no conflicts of interest in this work.

\section{References}

1. Siegel RL, Miller KD, Jemal A. Cancer statistics, 2018. CA Cancer J Clin. 2018;68(1):7-30.

2. Tsurusaki M, Murakami T. Surgical and locoregional therapy of HCC: TACE. Liver Cancer. 2015;4(3):165-175.

3. Yang B, Li CL, Guo WH, et al. Intra-arterial ethanol embolization augments response to TACE for treatment of $\mathrm{HCC}$ with portal venous tumor thrombus. BMC Cancer. 2018;18(1):101.

4. Jiang BG, Wang N, Huang J, et al. Tumor SOCS3 methylation status predicts the treatment response to TACE and prognosis in $\mathrm{HCC}$ patients. Oncotarget. 2017;8(17):28621-28627.
5. Huo YR, Eslick GD. Transcatheter arterial chemoembolization plus radiotherapy compared with chemoembolization alone for hepatocellular carcinoma: a systematic review and meta-analysis. JAMA Oncology. 2015;1(6):756-765.

6. Mokdad AA, Murphy CC, Pruitt SL, et al. Effect of hospital safety net designation on treatment use and survival in hepatocellular carcinoma. Cancer. 2018;124(4):743-751.

7. Liumbruno GM, Franchini M. Beyond immunohaematology: the role of the ABO blood group in human diseases. Blood Transfus. 2013; 11(4):491-499.

8. Franchini M, Mengoli C, Lippi G. Relationship between ABO blood group and pregnancy complications: a systematic literature analysis. Blood Transfus. 2016;14(5):441-448.

9. Peng H, Chen L, Li WF, et al. Prognostic correlations between ABO blood group and pre-treatment plasma Epstein-Barr virus DNA in patients with nasopharyngeal carcinoma receiving intensity-modulated radiotherapy. PLoS One. 2016;11(11):e0166194.

10. Zhou J, Yang LC, He ZY, Li FY, Wu SG, Sun JY. Prognostic impact of $\mathrm{ABO}$ blood group on the survival in patients with ovarian cancer. J Cancer. 2015;6(10):970-975.

11. Cozzi GD, Levinson RT, Toole H, et al. Blood type, ABO genetic variants, and ovarian cancer survival. PLoS One. 2017;12(4):e0175119.

12. Cao X, Wen ZS, Sun YJ, Li Y, Zhang L, Han YJ. Prognostic value of $\mathrm{ABO}$ blood group in patients with surgically resected colon cancer. Br J Cancer. 2014;111(1):174-180.

13. Park S, Kim KS, Kim JS, et al; Korean Breast Cancer Society. Prognostic value of $\mathrm{ABO}$ blood types in young patients with breast cancer; a nationwide study in Korean Breast Cancer Society. Med Oncol. 2017;34(6):118.

14. Vasan SK, Hwang J, Rostgaard $\mathrm{K}$, et al. ABO blood group and risk of cancer: a register-based cohort study of 1.6 million blood donors. Cancer Epidemiol. 2016;44:40-43.

15. Iavarone M, Della Corte C, Pelucchi C, et al. Risk of hepatocellular carcinoma in relation to ABO blood type. Dig Liver Dis. 2016;48(1): 94-96.

16. Tsurusaki M, Murakami T. Surgical and locoregional therapy of HCC: TACE. Liver Cancer. 2015;4(3):165-175.

17. Farinati F, Vitale A, Spolverato G, et al. Development and validation of a new prognostic system for patients with hepatocellular carcinoma. PLoS Med. 2016;13(4):e1002006.

18. Li X, Xu H, Ding Z, Jin Q, Gao P. Association between ABO blood group and $\mathrm{HCV}$-related hepatocellular carcinoma risk in China. Medicine. 2016;95(49):e5587.

19. Wu T, Ma XA, Wang GQ, et al. ABO blood type correlates with survival in hepatocellular carcinoma following hepatectomy. Sci Rep. 2017;7(1):4412.

20. Ouyang PY, Su Z, Mao YP, Liu Q, Xie FY. Prognostic value of ABO blood group in southern Chinese patients with established nasopharyngeal carcinoma. Br J Cancer. 2013;109(9):2462-2466.

21. Rahbari NN, Bork U, Hinz U, et al. AB0 blood group and prognosis in patients with pancreatic cancer. BMC Cancer. 2012;12:319.

22. Ko K, Park YH, Jeong CW, Ku JH, Kim HH, Kwak C. Prognostic significance of blood type A in patients with renal cell carcinoma. Urol J. 2016;13(4):2765-2772.

23. Sun $\mathrm{W}$, Wen $\mathrm{CP}$, Lin J, et al. ABO blood types and cancer risk - a cohort study of 339,432 subjects in Taiwan. Cancer Epidemiol. 2015;39(2): $150-156$.

24. Kakava K, Karelas I, Koutrafouris I, et al. Relationship between ABO blood groups and head and neck cancer among Greek patients. J BUON. 2016;21(3):594-596.

25. Allouh MZ, Al Barbarawi MM, Hiasat MY, Al-Qaralleh MA, Ababneh EI. Glioblastoma and $\mathrm{ABO}$ blood groups: further evidence of an association between the distribution of blood group antigens and brain tumours. Blood Transfus. 2016;15(6):543-547.

26. Unal D, Eroglu C, Kurtul N, Oguz A, Tasdemir A, Kaplan B. ABO blood groups are not associated with treatment response and prognosis in patients with local advanced non-small cell lung cancer. Asian Pac J Cancer Prev. 2013;14(6):3945-3948. 
27. Klatte $\mathrm{T}$, Xylinas E, Rieken M, et al. Effect of ABO blood type on mortality in patients with urothelial carcinoma of the bladder treated with radical cystectomy. Urol Oncol. 2014;32(5):625-630.

28. Yu J, Gao F, Klimberg VS, Margenthaler JA. ABO blood type/Rh factor and the incidence and outcomes for patients with triple-negative breast cancer. Ann Surg Oncol. 2012;19(10):3159-3164.

29. Duan YF, Zhu F, Li XD, et al. Association between ABO gene polymorphism (rs505922) and cancer risk: a meta-analysis. Tumour Biol. 2015;36(7):5081-5087.

30. Wang FM, Zhang Y, Zhang GM, Liu YN, Sun LJ, Liu Y. Association of ABO blood types and clinicopathological features of prostate cancer. Dis Markers. 2017;2017:9237481.

31. Terada T, Nakanuma Y. Expression of ABH blood group antigens, receptors of Ulex europaeus agglutinin I, and factor VIII-related antigen on sinusoidal endothelial cells in adenomatous hyperplasia in human cirrhotic livers. Hum Pathol. 1991;22(5):486-493.

32. Shahsavarzadeh T, Javanmard SH, Saadatnia M. Impact of factor VIII and von Willebrand factor plasma levels on cerebral venous and sinus thrombosis: are they independent risk factors? Eur Neurol. 2011;66(4):243-246.

33. Zhou S, Welsby I. Is ABO blood group truly a risk factor for thrombosis and adverse outcomes? World J Cardiol. 2014;6(9):985-992.
34. Tsimafeyeu IV, Demidov LV, Madzhuga AV, Somonova OV, Yelizarova AL. Hypercoagulability as a prognostic factor for survival in patients with metastatic renal cell carcinoma. J Exp Clin Cancer Res. 2009;28:30.

35. Zhang W, Xu Q, Zhuang Y, Chen Y. Novel association of soluble intercellular adhesion molecule 1 and soluble P-selectin with the ABO blood group in a Chinese population. Exp Ther Med. 2016;12(2): 909-914.

36. Shimizu Y, Minemura M, Tsukishiro T, et al. Serum concentration of intercellular adhesion molecule-1 in patients with hepatocellular carcinoma is a marker of the disease progression and prognosis. Hepatology. 1995;22(2):525-531.

37. Kobayashi H, Boelte KC, Lin PC. Endothelial cell adhesion molecules and cancer progression. Curr Med Chem. 2007;14(4):377-386.

38. Larson NB, Bell EJ, Decker PA, et al. ABO blood group associations with markers of endothelial dysfunction in the Multi-Ethnic Study of Atherosclerosis. Atherosclerosis. 2016;251:422-429.

39. The R Project for Statistical Computing. Available from: https://www.rproject.org/. Accessed May 15, 2018.
Therapeutics and Clinical Risk Management

\section{Publish your work in this journal}

Therapeutics and Clinical Risk Management is an international, peerreviewed journal of clinical therapeutics and risk management, focusing on concise rapid reporting of clinical studies in all therapeutic areas, outcomes, safety, and programs for the effective, safe, and sustained use of medicines. This journal is indexed on PubMed Central, CAS,

\section{Dovepress}

EMBase, Scopus and the Elsevier Bibliographic databases. The manuscript management system is completely online and includes a very quick and fair peer-review system, which is all easy to use. Visit http://www.dovepress.com/testimonials.php to read real quotes from published authors. 